\title{
UNDERSTANDING PEER AND TEACHER ASSESSMENT ABOUT LABORATORY SKILL ON FORMATIVE ASSESSEMENT THROUGH SCIENTIFIC APPROACH
}

\author{
Widinda Arlianty and Beta Febriana
}

Islamic University of Indonesia, Indonesia

\begin{abstract}
In order to obtain a holistic view of students's contribution peer assessment used in addition to teacher assessment to arrive at overall course grade of a students in scientific approach. However, students based assessment to determines final value still lots raises questions. Although, literature shown student based assessment useful to review and evaluate the right skills in scientific approach, but assessment between students and teacher have different perceptions toward viewpoints in assessments. Therefore, the aim of this study was to identify differences and similiarities between peer assessment and teacher assessment. The samples of this research were $2^{\text {nd }}$-semester were following physical chemistry experiment in the laboratory. The research was quasi experimental. The scope of this study is limited to laboratory skill in the laboratory and that were assessed using peer and teacher assessment. The data peer and teacher assessment were collected by observation sheet in experiment. Students in each group were asked to give confidential assessment to review laboraty skill of their group. The data analysis result indicate that students tend to give similiar scores to peers, which are much higher than what were given by their teacher. In conclusion, that student based assessment does provide information on laboratory skill of peers which may not accordance with assessment is given by teacher. Understanding that contributes that was privided by students againts assessment learning process is important as basic a review of teachers help students be learners have good laboratory skill through scientific approach.
\end{abstract}

Keywords: Peer Assessment, Teacher Assessment, Laboratory Skills

\section{Introduction}

In a learning process of many factors that influence the achievement of a goal. These factors consist of internal factors and external factors. Internal factors are usually derived from self-learners. While external factor is an external treatment that is expected to have a better effect on the achievement of learning objectives. The learning method is one of the factors that influence the learning process. Teachers typically use a variety of teaching methods to convey the subject matter in order to facilitate students in a lesson. Teachers always think of the learning method that will be used in the learning process. However, there are other important factors that actually contribute to the success of learning that assessment. Assessment serves as a feedback process that has been done and to encourage the learners to achieve better learning.

Assessment in learning activities important to know the achievements of students. Assessment does not only apply to the teaching and learning activities in the classroom or teaching theoretical level, but the assessment is also necessary for practical activities or that are of direct experience. The process of documenting, through the measurement process, knowledge, skills, attitudes, and beliefs of students called assessment. It can be stated also that the assessment is a systematic activity to obtain information about what is known, done, and done by students[6].

Assessment used in Department of Chemistry Education, Islamic University Indoneisa is assessment that has been determined by the lecturer of the course or assessment only focused on the lecturer and aided by

Corresponding Author: Widinda Arlianty/ widindanormaliaarlianty@uii.ac.id 
assistants. This assessment is used to determine the students' ability to work in laboratoium. However, the assessment is only done by lecturers and assistants have not been able to assess the overall activities in the laboratory. Therefore, the assessment is necessary to assist the faculty in assessing the ability of the individual laboratory. This is done so that the student's ability to work in a laboratory could actually measured. Proper assessment and can help in assessing the skills of students in the laboratory is through peer assessment.

Peer Assessment is commonly known as peer assessment where the assessment carried out by their own friends. Assessment of the requested information on the performance of students from other students[4]. In addition they also suggested that peer assessment is the process by which one team or group assess each group member friend and judge based on information that has been collected. But others argue that the peer assessment involves students provide feedback on the quality of work of their friend. Assessment peers requires students to pass judgment on the performance, and excellence of other friends in deciding their involvement in these activities. The assessment uses peer assessment helps reduce the subjectivity of education in this case the teacher or lecturer in assessing the learning process[7]. Implementation of peer assessment helps build student confidence. Assessment conducted by colleagues to help students better prepare themselves to be more competent.

Characteristics include peer assessment, peer assessment is a process whereby each member of a team doing assess, then goal setting should be understood students well. Peer assessment as an alternative assessment gives students the freedom to express opinions. Identified several advantages of peer assessment include: (1) peer assessment can improve the learning process, (2) to identify the weaknesses and strengths of students in learning, (3) encourage to learn more in-depth and meaningful (4) encourage the learning does not depend on others, (5) can recognize that transparent assessment criteria for assessment, (6) push for mutually analyzing the performance or results of each working group's friends[5].

Peer assessment and self-assessment has great potential to the understanding of mathematics student teachers[3]. In another opinion, shows that the self-assessment and peer can be applied to courses that discuss the concepts and relationships between concepts [1]. The practice of self-assessment and peer assessment in colleges and schools are lacking, while the teacher is actually a positive perception of the benefit of selfassessment and peer and there is potential for wide application[2].

Implementation of the assessment in the laboratory can be done easily if the learning process in the laboratory is well designed using a variety of methods, models, or the right learning approach. Suitable learning approach applied in the laboratory activities is through a scientific approach. The scientific approach is an approach to learning that is now often used in the learning process in the laboratory. In a scientific approach consists of several process of observing (Observing), ask (Questioning), reasoning (associating), try (experimenting), concluded and forming networks (Networking). Through this activity, the students will be assessed contribution through the assessment given by the teacher (teacher assessment) as well as peer assessment (peer assessment) [8,9].

Practicum courses organized to provide laboratory skills and mastery of the material to the maximum. Implementation of the practicum course very important to support the learning outcomes. Course practicum is a means to strengthen, proved, finding a theory derived from the lectures in class. Hopefully, by the learning by using a scientific approach as well as peer assessment and teacher assessment on practicum courses can not only produce students have competence in the areas of knowledge, but also skills and attitudes. 


\section{Research methods}

\section{Research design}

This research is quasi-experimental research design with Intact-Group Comparison. Experimental research paradigm in this model are presented in Table 1 below.

Table 1. Research Desaign

\begin{tabular}{cc}
\hline $\begin{array}{c}\text { Class of Research } \\
(\mathbf{X})\end{array}$ & $\begin{array}{c}\text { Assessment of Reseacrh } \\
(\mathbf{O})\end{array}$ \\
\hline Experimental Class $\left(\mathrm{X}_{\mathrm{a}}\right)$ & Peer Assessment $\left(\mathrm{O}_{1)}\right.$ \\
Convensional Class $\mathrm{X}_{\mathrm{b}}$ & Teacher Assessment $\left(\mathrm{O}_{2}\right)$ \\
\hline
\end{tabular}

\section{Research Subjects}

Subject in this study consisted of 44 students, divided into 2 of 23 students to a class with peer assessment (experimental class) and 21 students to a class with a teacher assessment (conventional classes). These two classes have the same academic ability. Table 2 and Table 3 below.

Table 2. Frequences and Precentages

\begin{tabular}{ccc}
\hline \multirow{2}{*}{ Gender } & Peer Assessment Class & Teacher Assessment Class \\
& $\mathbf{N}(\boldsymbol{\%})$ & $\mathbf{N}(\boldsymbol{\%})$ \\
\hline Males & 1 & 4 \\
Females & 22 & 17 \\
\hline Total & $\mathbf{2 3}$ & $\mathbf{2 1}$ \\
\hline
\end{tabular}

Table 3. Descriptive on pretest score

\begin{tabular}{ll}
\hline \multicolumn{1}{c}{ Class of Assessment } & Average \\
\hline Peer Assessment Class (PAC) $(\mathrm{N}=24)$ & 87,70 \\
Teacher Assessment Class (TAC) $(\mathrm{N}=20)$ & 82,14 \\
\hline
\end{tabular}

\section{Research Instruments}

Data collection research using peer assessment and teacher assessment. The instrument used to assess the ability of the students in the laboratory. An instrument which is used in the form of observation sheet. This observation sheet contains about skills using the tools that are tailored to the laboratory procedures were implemented. In the practical implementation of feedback obtained through formative assessment. Assessment for experimental class taken from assessment through peer assessment skills, knowledge through prettest and reports and posttest. Ratings for conventional classes, skills assessment obtained through teacher assessment, knowledge gained through prettest, reports and posttest. The items used to assess the skills of peers ang teacher assessment are shown in Table 4 and Table 5. Then peer assessment instrument validation using the formula Gregory presented in Figure 1.

Table 4. Peer Assessment items used to assess skill in laboratory

\begin{tabular}{cl}
\hline No & Skills are using laboratory equipment \\
\hline 1 & The ability to use drop pipette \\
2 & The ability to use Burette \\
\hline 3 & The ability to use Calorimeter \\
\hline 4 & The ability to use Volume pipette \\
\hline 5 & The ability to use Multimeter \\
\hline 6 & The ability to use Thermometer \\
\hline 7 & The ability to use Filter paper \\
\hline 8 & The ability to use Flask \\
\hline
\end{tabular}




\begin{tabular}{cl}
9 & The ability to use Analytical Balance \\
\hline 10 & The ability to use Measuring cup \\
\hline 11 & The ability to use Viscometer \\
\hline 12 & The ability to use Tube Hoppler \\
\hline
\end{tabular}

Table 5. Teacher Assessment items used to assess skill in laboratory

\begin{tabular}{cl}
\hline No & Skills in the laboratory \\
\hline 1 & Wear clothing and protective clothing \\
2 & Engineering and laboratory safety \\
\hline 3 & Activeness in the laboratory \\
\hline 4 & Accuracy and precision of results \\
\hline 5 & Interim report \\
\hline & Content Validity $(\mathrm{CV})=\frac{\mathrm{D}}{\mathrm{A}+\mathrm{B}+\mathrm{C}+\mathrm{D}}$ \\
\end{tabular}

Figure 1. Formula Formula Gregory
A : The number of items that are less relevant by both panelists
B : The number of items that are less relevant according to the first panel and relevant according to panelists II
C : The number of items that are relevant according to the first panel and less relevant according to panelists II
D : The number of the relevant item by both panelists

\section{Research Procedure}

The experimental gruoup was taught scientific approach. The use of the approach performed on laboratory experiments. The scientific approach consists of 5 points, namely Observing, Questioning, associating, experimenting, Networking. Conventional classroom learning that is practical in accordance with existing rules in the university environment. They undergo a learning process using scientific approaches and conventional for eight weeks. Every practical implementation will be assessed using peer assessment for the experimental class and teacher assessment for conventional classroom. This assessment is held up to the seventh practical implementation is resolved. At the end of the practicum was held posttest in experimental classes and conventional classes. Chronology of the application of peer assessment and teacher assessment are presented in Figure 2 and Figure 3 below.

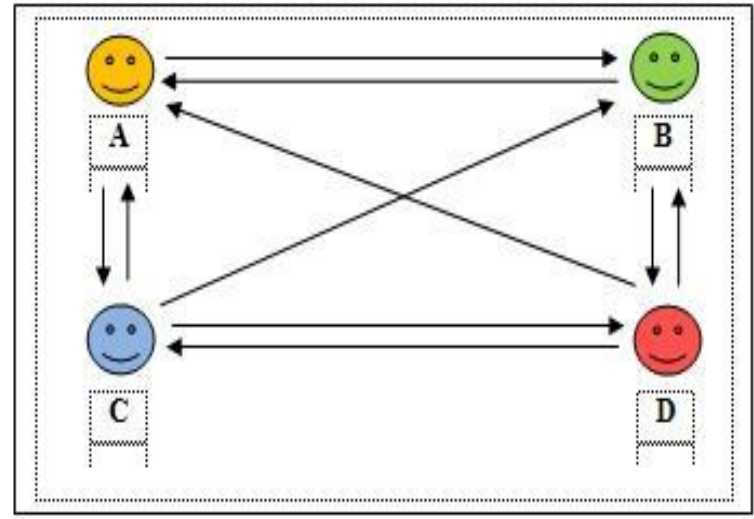

Figure 2. Peer Assessment Implementation Flow 


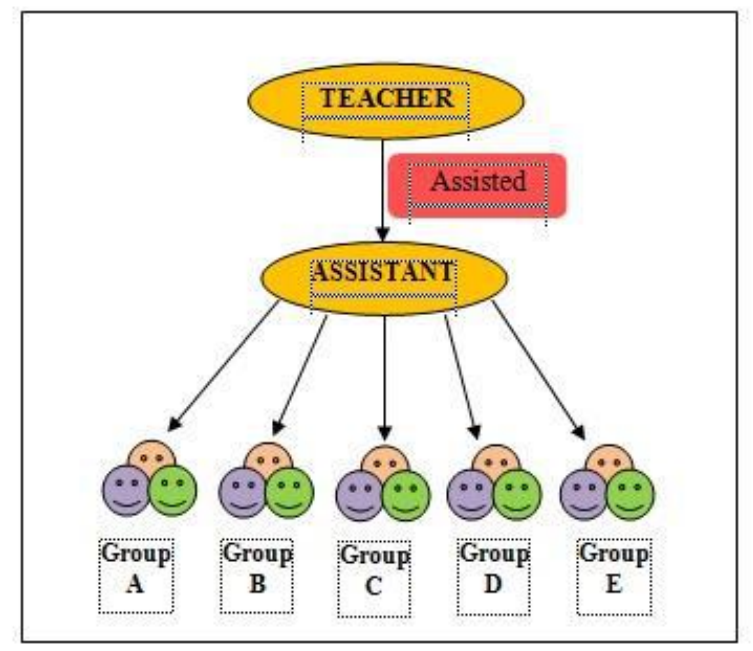

Figure 3. Teacher Assessment Implementation Flow

\section{Data Analysis and Results}

\section{Instrument Validation Results}

The results of the validation instrument gregory peer assessment using the formula presented in Table 6 below.

Table 6. Summary of Results of Content Validity Test Instruments Peer Assessment

\begin{tabular}{cccc}
\hline Variable & $\begin{array}{c}\text { The number of } \\
\text { Indicator }\end{array}$ & $\mathrm{CV}$ & Conclusion \\
\hline Peer Assessment Instrument & 19 & 0,95 & $\begin{array}{c}\text { Analysis can be } \\
\text { continued }\end{array}$ \\
\hline
\end{tabular}

\section{Result of Peer and Teacher Assessment}

Results of this study was obtained from several assessments on the assessment and peer classroom teacher classroom assessment. The results of such assessment have been presented in Table 7 and Figure 4. below.

Table 7. Descriptive Between Peers and Teacher Assessment Score

\begin{tabular}{lcc}
\hline \multicolumn{1}{c}{ Assessment Aspect } & $\begin{array}{c}\text { Experimental Class } \\
\text { (Peer Assessment Class) }\end{array}$ & $\begin{array}{c}\text { Convensional Class } \\
\text { (Teacher Assessment) }\end{array}$ \\
\hline Pretest & 87,70 & 82,14 \\
Laboratory Skills & 91,90 & 86,77 \\
Report & 86,32 & 77,13 \\
Postest & 41,56 & 35,39 \\
\hline
\end{tabular}




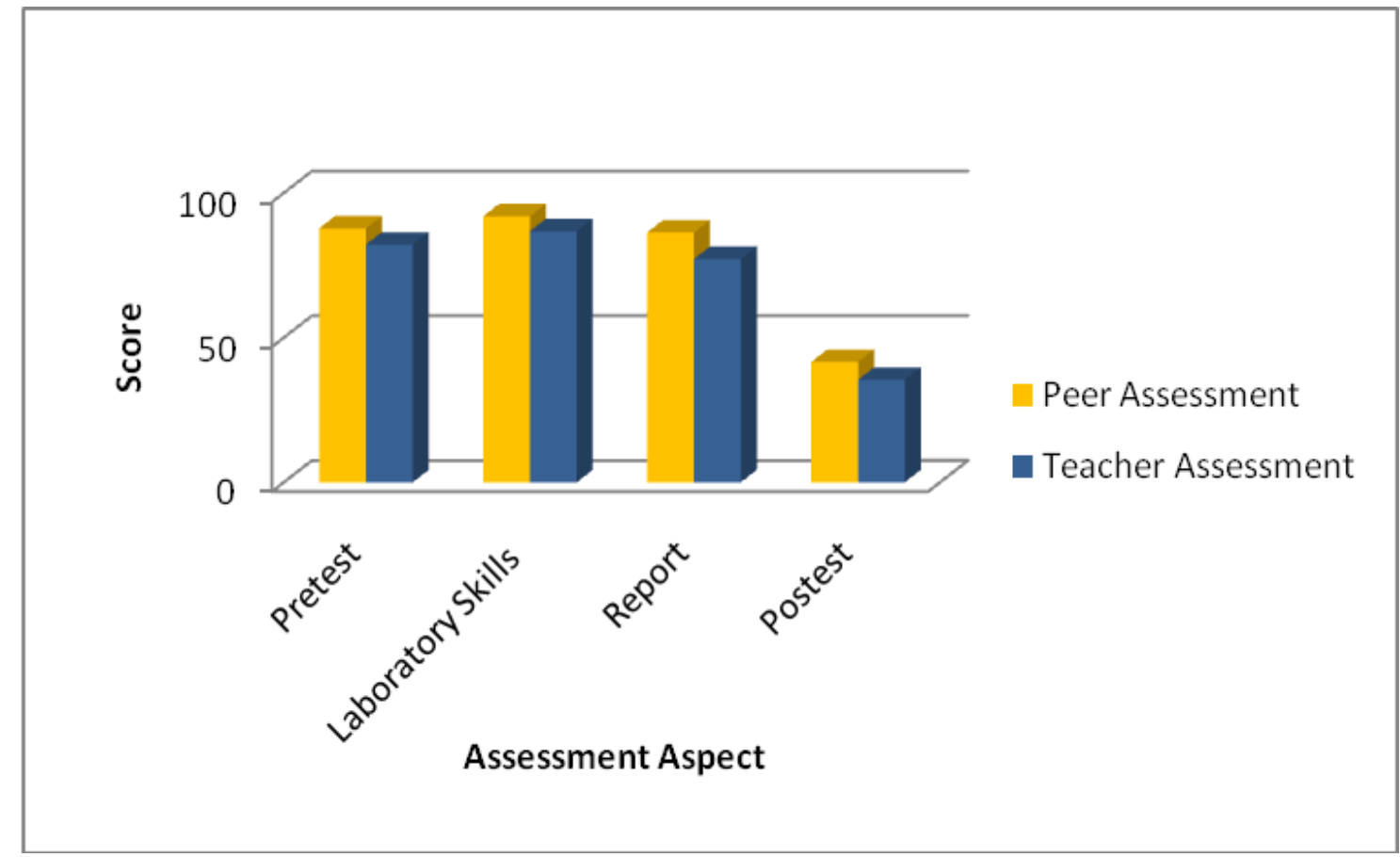

\section{Result and Discussions}

Implementation of this research aims to determine the value of peers and teacher assessment on practicum courses. The research was carried out for eight weeks, with one posttest.

The instrument used in this study is the instrument of peer assessment and teacher assessment. Teacher assessment instruments have been defined by the faculty so no need to hold validation. Instruments peer assessment before being used for carrying out research assessment validated in advance by the validator because it has not been used. Validation is used for peer-assessment instrument that is validating the content using a formula gregory. Results of validation using Gregory namely Content Validity $(\mathrm{CV})=0.95$, it indicates that the analysis can be continued. In another sense the instrument is validated and can be used to assess a study.

Implementation of research conducted in the laboratory. Students carry out practical work for eight weeks. Practical implemented, students are assessed using peer and teacher assessment .. Rating peers used to assess the ability of laboratories student or students' skills when carrying out laboratory experiments. Assessment of the teacher, graded by the teacher assistant helped to get the value of laboratory skills as well as to match the truth results of peer assessment.

Based on the results in Table 7 and Figure 4 can be seen that the value of the experimental class has a different value with the value in the conventional class (teacher assessment). The value of the experimental class has an average value which is better than the conventional classroom. The application of the scientific approach to the ability of laboratories can be seen on the assessment of skills in the classroom aspect of peer and teacher assessment. From the assessment indicates that the peer assessment ratings and teacher ratings have a value that is not much different although higher than the peer assessment teacher ratings. This was confirmed by previous studies related to self-assessment and peer compatible to the student-centered learning. From the research results concluded that the self-assessment and peer positive effect on student learning outcomes, which can improve learning outcomes and increase their desire to learn. In another study also concluded that the self-assessment and peer into their facilities in the lucrative receive feedback from their group of friends, as the critical success factors in their group learning[11]. 
Assessment of peer assessment contains the assessment of mastery of laboratory equipment that will be used by students in the laboratory. Students use a variety of tools such as the chemical laboratory, burette; pippete drop, volume pipette, stirrer, thermometer, flasks and others. This assessment is carried out in order to give the ability laboratory students department of chemical education. Peer assessment is carried out in a way students were divided into several groups. Furthermore, each group will assess the friends in one group. Suppose that in a group consisting of four members, each member will assess the other three members. Assessment using observation sheet where students are given guidelines and scoring rubric that will be used to assess which have been validated by a validator. The results of this assessment turned out to be quite a strong effect in addition to the academic field. Students when assessed by their friends feel that they have to do the best practice, so the students' performance in the laboratory is maximal. But also did not deny that there are weaknesses of peer assessment. When students are in a group that feels the same ability, or below, it will plan to judge the same thing from the whole member. Assessments can be used to cross-check the results of peer assessment is an assessment of the teacher. Assessment from the teacher is an assessment that has the same goal is to determine the ability of student laboratories. The results of these assessments are used to minimize the level of subjectivity peer assessment has been used on previous students.

Implementation of the assessment peer and teacher equally influential on student achievement. From Table 7 shows that the difference between these two values are not much different on each aspect. This difference indicates that the assessment is done through peer assessment provide more opportunities to students in assessing his friend. Truth values given student can crosscheck through teacher assessment. Formative assessment can be obtained from a variety of additional value in addition to the laboratory skills such as pretest assessment and reports. These assessments help provide feedback that can help improve the learning process in the laboratory. The formative assessment can encourage active learning process student-centered[10]. Feedback provided by students is an important component that can be used to improve the learning process.

\section{Conclusion}

The purpose of this research is to know the difference and similarity between assessment using peer and teacher assessment with scientific approach to know the ability of laboratory. Based on research that has been done that peers and teacher assessment affect the ability of the student laboratory. Know the influence of peers and teacher assessment assessment is important to help students to develop students' freedom in knowing the assessments performed so that students can learn from the transparency of the existing value to optimize its ability.

\section{Acknowledge}

Authors would like to thank the Academic Development Agency (BPA) Islamic University of Indonesia who have given the opportunity to be one of the recipients Regular Teaching Grant Program in the second semester of the 2015/2016 academic year.

\section{References}

Matsuno, S., 2009, Self, peer, and teacher-assessments in Jananese university EFL writing classrooms, Language testing, 28 (1),75-100.

Noonan, B., \& Duncan, R., 2005, Peer and self-assessment in high school, Practical Assessment Research \& Evaluation, 10 (17), 1-8.

Xin Ma, Millman, R., \& Wells, M., 2008, A self and peer assessment intervention in mathematics content courses for pre-service elementary school teacher.

Kiliq, E, D., 2007, Measure for university student' attitude towards peer assessment, Sanliurfa: Harran University

Majduddin, Khadijah., 2010, Peer assessment alternative to traditional testing. Teheran: University of Tehran.

Rifa i, A., \& Catharina, T.A., 2009, Psikologi pendidikan, Semarang: UNNES Press. 
Falchikov, N. \& Goldfinch, J, 2000, Student peer assessment in higher education: A meta-analysis comparing peer and teacher marks. Practical Assessment Research \& Evaluation, 70 (3): 287-322

Mac Donald, R.F. \& Savin-Baden, M., (2004) “A Briefing on Assessment in Problem-based Learning," LTSN Generic Centre Assessment Series. Available on the Higher Education Academy's Resource.

Kolmos, A. \& J.E. Holgaard., 2007, Alignment of PBL and assessment.1stInternational Conference on Research in Higher Education. Honolulu: American Educational Research Association, pp. 1-9.

Wahab, H. F. A., dkk. 2008. Penggunaan penilaian formatif sebagai proses melengkapkan gelung: satu usaha penembahbaikan. Makalah seminar

Willey, K. \& Gardner, A. P., 2007, Investigating the capacity of self and peer assessment to engage student and incease their desire to learn. 